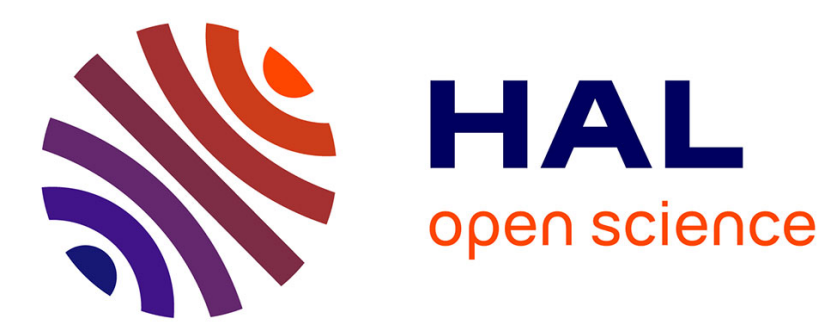

\title{
Design and Characterization of a Micromachined Receiver for W Band Applications
}

Alina-Cristina Bunea, Dan Neculoiu, Alexandru Takacs, Pierre-François Calmon

\section{- To cite this version:}

Alina-Cristina Bunea, Dan Neculoiu, Alexandru Takacs, Pierre-François Calmon. Design and Characterization of a Micromachined Receiver for W Band Applications. European Microwave Week (EuMW), Oct 2014, Rome, Italy. 4p. hal-02066088

\section{HAL Id: hal-02066088 \\ https://hal.laas.fr/hal-02066088}

Submitted on 13 Mar 2019

HAL is a multi-disciplinary open access archive for the deposit and dissemination of scientific research documents, whether they are published or not. The documents may come from teaching and research institutions in France or abroad, or from public or private research centers.
L'archive ouverte pluridisciplinaire HAL, est destinée au dépôt et à la diffusion de documents scientifiques de niveau recherche, publiés ou non, émanant des établissements d'enseignement et de recherche français ou étrangers, des laboratoires publics ou privés. 


\section{Design and Characterization of a Micromachined Receiver for W Band Applications}

\author{
Alina-Cristina Bunea ${ }^{1,2}$, Dan Neculoiu ${ }^{1,2}$ \\ ${ }^{1}$ IMT Bucharest, Bucharest, Romania \\ ${ }^{2}$ Politehnica University of Bucharest, Bucharest, Romania \\ alina.bunea@imt.ro, dan.neculoiu@imt.ro
}

\author{
Alexandru Takacs ${ }^{3}$, Pierre Calmon ${ }^{3}$ \\ ${ }^{3}$ CNRS, LAAS; Univ de Toulouse, \\ Toulouse, France \\ atakacs@laas.fr, calmon@laas.fr
}

\begin{abstract}
This paper presents for the first time the design, electromagnetic modeling and simulation of a W-band micromachined receiver with a double folded slot antenna. The antenna was processed on a thin dielectric membrane obtained through wet micromachining of a $400 \mu \mathrm{m}$ thick, high-resistivity silicon substrate. A stand-alone antenna structure was fabricated and characterized in terms of reflection losses, showing a working band (defined for $|\mathrm{S} 11|<-10 \mathrm{~dB}$ ) between 88.3 - $105.8 \mathrm{GHz}$, in good agreement with simulations. The maximum simulated directivity at $94 \mathrm{GHz}$ is $6.3 \mathrm{dBi}$. The direct conversion receiver uses a hybrid integrated GaAs zero bias detector diode. Two new parameters based on the incident isotropic power are introduced: isotropic voltage sensitivity and isotropic tangential signal sensitivity. The measured isotropic tangential sensitivity is lower than - $40 \mathrm{dBm}$ between 80 - $105 \mathrm{GHz}$, for a $10 \mathrm{kHz}$ video bandwidth.
\end{abstract}

Keywords—direct detection receivers; slot antennas; $W$ band; zero bias detectors.

\section{INTRODUCTION}

The W-band is becoming the range of choice for numerous applications, from high-data rate communications to automotive radar systems and most of all, passive/active millimeter wave imaging (MMWI) applications. But most solutions make use of bulky horn antennas and complicated waveguide transitions in order to collect the electromagnetic radiation from the target scene. A more cost-efficient approach consists in monolithically or hybrid integrating an on-chip antenna with a detector diode and possibly a low-noise amplifier. This (quasi-)planar approach can reduce the losses, reduce the overall receiver size and simplify the packaging.

A receiver with two slots, connected by two microstrip sections and hybrid integrated with a Schottky diode was first described by Kerr et al. [1] in the late '70s. The approach was considered innovative at the time and tried to solve some of the issues related to quasi-optical mixers, like the energy transfer from the local oscillator to the diode, which required complicated waveguide couplers. The new approach generated the required coupling through the two lobes of the antenna.

Based on the idea of placing a detector between two radiating slots, researchers strived, in the ' 90 s, to fabricate highly compact and performant millimeter wave receivers [2]-[4].

This work was supported by the FP7 project NANOTEC (no. 288531) and the National Romanian Research Authority and the National Funding Agency from France (Region Midi-Pyrenees) through the MNT ERA NET project MEMIS. The Romanian authors acknowledge the support of the Romanian Ministry of National Education, under the project no. PN-II-IDPCE-2011-3-0830.
One of the first papers describing a double folded slot antenna radiometer is [4]. The receiver was fabricated on a GaAs substrate and hybrid integrated with a Schottky diode and a low-noise amplifier (LNA). The working bandwidth was $20-22 \mathrm{GHz}$.

Some of the main issues in obtaining a fully integrated on-chip front end in modern SiGe BiCMOS technologies, are related to the low performances and large sizes of antennas [5]. This is mainly due to the lossy substrates. One possible solution to this problem consists of removing the lossy silicon from under the radiating structure. Such an approach was presented in [6], for a dipole antenna working in the $83-91 \mathrm{GHz}$ frequency range, with a maximum gain of $4 \mathrm{dBi}$ at $85 \mathrm{GHz}$.

In this paper we present a novel topology of a $\mathrm{W}$ band hybrid integrated receiver consisting of a membrane supported double folded slot antenna, followed by a GaAs beam lead detector diode. First, a standalone antenna test structure was designed, fabricated and characterized in terms of reflection losses and radiation behavior. The next step consisted of integrating the antenna with a matching network, a set of diode pads and a low-pass filter. The diode was hybrid integrated using conductive epoxy. The front-end was then characterized in terms of isotropic voltage sensitivity and isotropic tangential signal sensitivity (TSS).

\section{MICROMACHINED ANTENNA}

A fully parameterized 3D model was developed using the full-wave finite-difference time-domain electromagnetic simulation tool CST Microwave Studio (MWS), Fig. 1.

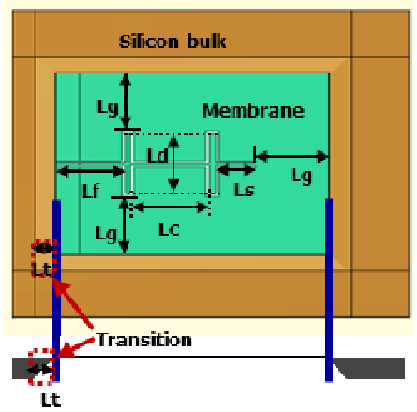

Fig. 1. Layout of the membrane suported double folded slot antenna 
The antenna structure was designed for anisotropic wet micromachining of a $400 \mu \mathrm{m}$ thick high resistivity $(>5 \mathrm{k} \Omega \bullet \mathrm{cm})$ $<100>$ silicon wafer. This results in a sloped transition (at an angle of $54.7^{\circ}$ ) from the released membrane to the silicon bulk (see Fig. 1), which was included in the 3D model.

The membrane consists of a $0.8 \mu \mathrm{m}$ silicon oxide layer, obtained through thermal oxidation, followed by a $0.6 \mu \mathrm{m}$ silicon nitride layer, obtained through chemical vapor deposition. The metallization consists of a $2 \mu \mathrm{m}$ thick gold layer, obtained through electrochemical deposition.

The membrane supported antenna consists of two folded slots, connected by a coplanar waveguide (CPW) transmission line of half free-space wavelength $\left(\lambda_{0} / 2 \approx 1595 \mu \mathrm{m}\right.$ at $94 \mathrm{GHz}$ ). A shorted stub of length Ls (close to $\lambda_{0} / 4$ ) is added to help tune the matching characteristic and symmetrize the layout. Extensive parametric studies with the main objective of determining the best trade-off between matching and radiation behavior were run in order to determine the layout parameters. The final geometrical sizes are as follows: $\mathrm{Lg}=2200 \mu \mathrm{m}$, $\mathrm{Ld}=1550 \mu \mathrm{m}, \mathrm{Lc}=1370 \mu \mathrm{m}, \mathrm{Ls}=710 \mu \mathrm{m}, \mathrm{Lf}=1320 \mu \mathrm{m}$, $\mathrm{Lt}=282.8 \mu \mathrm{m}\left(\mathrm{Lt}\right.$ is computed for the transition angle of $54.7^{\circ}$ and substrate thickness $\mathrm{hSi}=400 \mu \mathrm{m}$ ).

Fig. 2a shows the electric field distribution in the slots at $94 \mathrm{GHz}$. Since the E-field is in phase in both folded slots, the energy is radiated normal to the antenna plane. Because the antenna is suspended on a very thin dielectric membrane, it operates as if suspended in air and has an almost symmetrical radiation characteristic, with two main lobes (Fig. 2b).

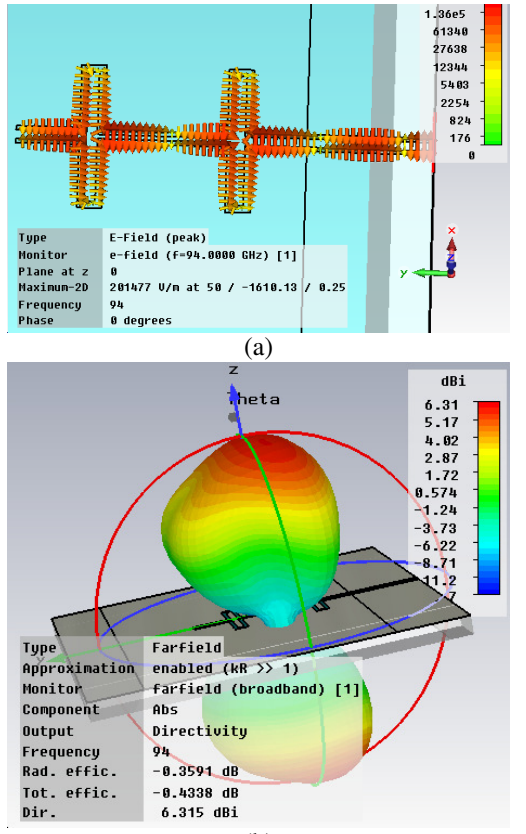

(b)

Fig. 2. (a) Electric field distribution and (b) 3D radiation characteristic at $94 \mathrm{GHz}$

The maximum simulated directivity at $94 \mathrm{GHz}$ is $6.3 \mathrm{dBi}$, with a $3 \mathrm{~dB}$ beam-width of $58.6^{\circ}$ in the E plane (parallel to the feed line) and $80^{\circ}$ in the $\mathrm{H}$ plane.
The 3D electromagnetic model was validated through on wafer measurements. The antenna was placed on a PCB, over an opening, in order to ensure free space conditions for the second lobe. Reflection loss measurements were performed with a Vector Network Analyzer (Anritsu 37397D) with OML extension modules. A comparison between the measured and simulated results is shown in Fig. 3. The measured bandwidth $(|\mathrm{S} 11|<-10 \mathrm{~dB})$ is between $88.3-105.8 \mathrm{GHz}$, with $|\mathrm{S} 11|=-29.7 \mathrm{~dB}$ at $94 \mathrm{GHz}$.

A standard gain horn antenna was connected to the second port of the VNA and suspended at a distance of $100 \mathrm{~mm}$ over the antenna under test. The measured transmission characteristic is presented in Fig. 4 (left axis, the maximum of the curve was set to $0 \mathrm{~dB}$ reference level). On the same plot, the simulated antenna gain is presented (right axis) for comparison. The trend of the two curves is similar, thus proving good radiation behavior of the antenna.

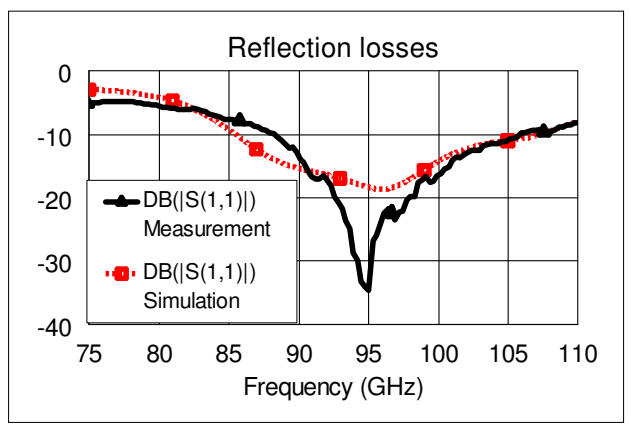

Fig. 3. Measured (solid line) and simulated (dotted line) reflection losses for the antenna

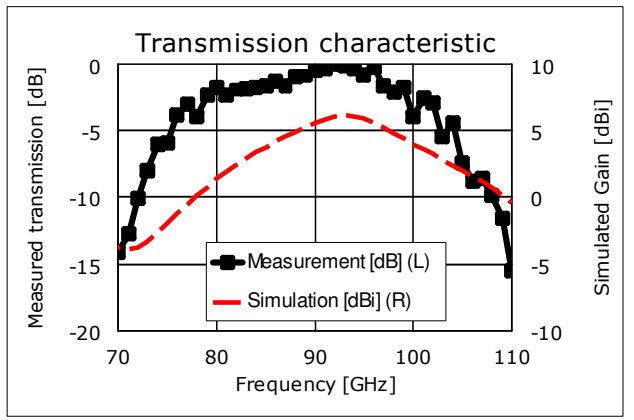

Fig. 4. Measured transmission characteristic (solid line, left axis) and simulated gain (dotted line, right axis)

\section{RECEIVER TOPOLOGY AND MEASUREMENTS}

The receiver module is a direct conversion (video) receiver and a photo of the fabricated structure is presented in Fig.5. One block is the double folded slot antenna supported on the thin dielectric membrane. The signal is then converted to a DC/low-frequency signal by the nonlinear characteristics of the detecting diode. The detecting diode is placed in series between the matching network connected to the antenna and the lowpass filter. The matching network has a stub-line configuration, 
with a CPW symmetrical shorted stub. The low-pass filter consists of a cascade of CPW low-impedance/high-impedance sections. This filter extracts the DC/low-frequency signal, removes high order spectral components and reflects the $\mathrm{W}$ band signal back to the detector diode. The overall receiver structure is designed to provide the correct DC return for the detecting diode. The output of the low-pass filter is connected to the low-frequency (video) output pad. The video signal is then picked up from the chip through bond wires and a coaxial cable.

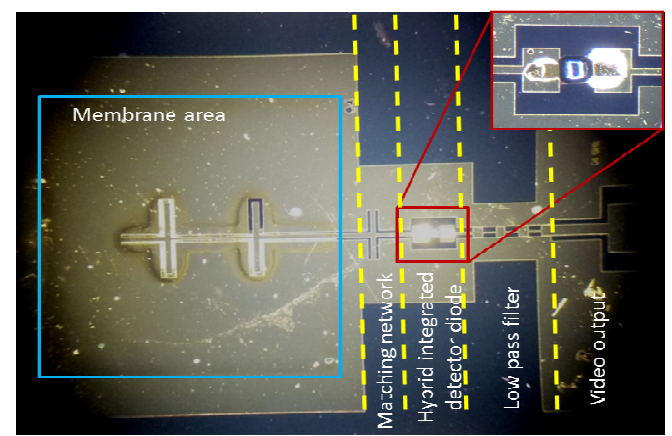

Fig. 5. Photo of the hybrid integrated receiver structure with a detail of the GaAs beam lead zero bias detector diode

With the help of microwave simulation software AWR Design Environment and CST MWS, the circuit blocks (antenna, matching network, low-pass filter and diode) are linked together and the receiver layout is optimized.

The Aeroflex/Metelics MZBD-9161 is a GaAs beam lead detector diode and it is intended for zero bias detecting applications at frequencies up to $110 \mathrm{GHz}$. The data sheet main electrical specifications are: junction capacitance $\mathrm{C}_{\mathrm{j}}=0.035 \mathrm{pF}$ and video resistance at zero bias $\mathrm{R}_{\mathrm{V}}=2.5-7.5 \mathrm{k} \Omega$. The diode is mounted using conductive epoxy on two rectangular pads (inset in Fig.5). In the electromagnetic design, the device is inserted in the model using the discrete port feature of the CST MWS software. For this detecting application the diode was modeled with its small signal equivalent circuit.

The micromachined structure was mounted on a printed circuit board (PCB) above an opening that allows the quasifree space operation for the antenna. The opening was covered with $\mathrm{W}$ band absorber, in order to suppress the influence of the second lobe of the micromachined antenna. The experimental set-up is presented in Fig.6.

The receiver (1 in Fig.6) is illuminated by a horn antenna (2) connected to a millimeter $(\mathrm{mm})$ - wave source through a W band attenuator Millitech LSA-10 (3). The signal source was a PSG Analog Signal Generator (Agilent E8257C) going up to $110 \mathrm{GHz}$ with a S10MS-AG extension module (4). The standard horn antenna QWH-WPRR00 has a mid-band gain of $24 \mathrm{dBi}$. The transmitted signal was modulated in amplitude by a $1 \mathrm{kHz}$ square wave with a modulation index of $100 \%$ and the detected waveform was amplified by a SR560 LNA (5) and displayed on a Agilent Tech. DSO1024A oscilloscope (6).

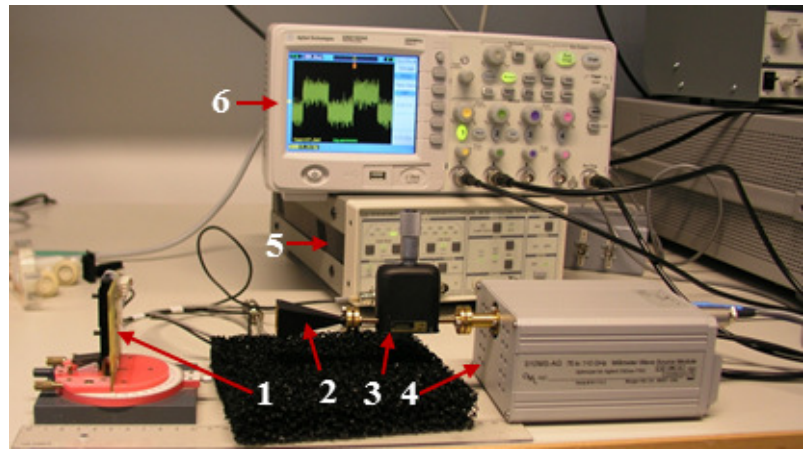

Fig. 6. Measurement setup for the receiver characterization (see text for details)

The PCB holder for the receiver was placed at a distance of $100 \mathrm{~mm}$ from the horn antenna (far field conditions for $\mathrm{W}$ band). Since the circuit combines the function of the antenna and a detector, the isotropic voltage sensitivity $\beta_{\text {iso }}$ parameter is used to characterize the efficiency of the receiver. $\beta_{\text {iso }}$ is defined as the ratio between the detected output voltage and the incident isotropic power (similar to the isotropic conversion loss defined in [7]).

The incident isotropic power at the membrane supported antenna plane is calculated with (1).

$$
\mathrm{P}_{\text {iso }}=\mathrm{P}_{\text {gen }} \mathrm{G}_{\text {Horn }}\left(\frac{\lambda}{4 \pi \mathrm{R}}\right)^{2},
$$

where: $\lambda$ is the free-space wavelength; $\mathrm{R}$ is the distance between the horn antenna and the double folded slot antenna ( $\mathrm{R}=100 \mathrm{~mm}$ in this experiment); $\mathrm{G}_{\mathrm{Horn}}$ is the gain of the horn antenna ( $24 \mathrm{dBi}$ in this case) and $\mathrm{P}_{\text {gen }}$ is the power level at the output of the rectangular waveguide connecting the horn antenna.

$\mathrm{P}_{\text {gen }}$ was accurately measured with a $\mathrm{W}$ band power-meter in the $\mathrm{W}$ band. The detected voltage amplitude was measured on the oscilloscope and the $\beta_{\text {iso }}$ is calculated and presented in Fig.7 (left axis). These results can be improved by ensuring a better matching of the junction resistance of the diode (which is in the range of a few $\mathrm{k} \Omega$ ) to the standard characteristic impedance of $50 \Omega$.

Despite of its subjective nature, tangential signal sensitivity (TSS) remains a practical technique to estimate the noise equivalent power (NEP) for a detector [8]. In the present work a new parameter, called isotropic TSS $\left(\mathrm{TSS}_{\text {iso }}\right)$, is defined, using the input power $\left(\mathrm{P}_{\text {iso }}\right)$ equation from (1). It gives precious information about the minimum detectable signal and makes the comparison between different receivers with integrated antennas possible. Using a variable $\mathrm{W}$ band attenuator connected between the generator and the horn antenna (Fig.6) the emitted power level was reduced to fulfill the TSS measurement conditions and $\mathrm{P}_{\mathrm{gen}}$ was measured. The measured value for a video bandwidth of $1 \mathrm{~Hz}-10 \mathrm{kHz}$ is shown in Fig.7 (right axis). 


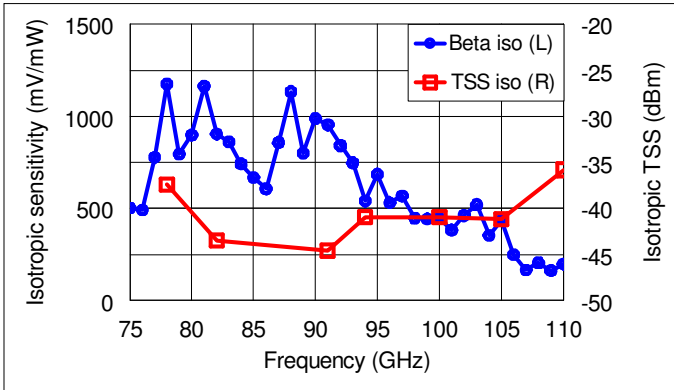

Fig. 7. Measured isotropic voltage sensitivity (left axis) and isotropic tangential signal sensitivity (right axis)

The peak value for the isotropic voltage sensitivity is around $1150 \mathrm{mV} / \mathrm{mW}$ at $78 \mathrm{GHz}, 81 \mathrm{GHz}$ and $88 \mathrm{GHz}$ and can be considered state of the art, since it also includes the effect of the on-chip antenna. The measured isotropic TSS (taking into account the effect of the on-chip antenna) is below $-40 \mathrm{dBm}$ between $80-105 \mathrm{GHz}$, for a $10 \mathrm{kHz}$ video bandwidth.

For comparison, [9] describes a broadband millimeter wave slotline detector with a peak voltage sensitivity of $1660 \mathrm{mV} / \mathrm{mW}$ at $77 \mathrm{GHz}$, without any antenna and with a DC biased diode. A TSS around $-46 \mathrm{dBm}$ at $77 \mathrm{GHz}$ is achieved for a video bandwidth of $1 \mathrm{kHz}$ [9]. It should be noted that the difference in TSS is $5 \mathrm{~dB}$ for an increase of the video bandwidth from $1 \mathrm{kHz}$ to $10 \mathrm{kHz}$ [8].

\section{CONCLUSION}

A hybrid integrated receiver consisting of a membrane supported double folded slot antenna, followed by a GaAs beam lead detector diode for $\mathrm{W}$ band applications was presented. The standalone antenna test structure showed a wide working band (defined for $\mid \mathrm{S} 11 \mathrm{~K}-10 \mathrm{~dB}$ ) between $88.3-105.8 \mathrm{GHz}$, with $|\mathrm{S} 11|=-29.7 \mathrm{~dB}$ at $94 \mathrm{GHz}$. With the help of a reference horn antenna, a good radiation behavior was demonstrated. The experimental results are in good agreement with the simulated reflection loss and antenna gain.
The voltage sensitivity and the tangential signal sensitivity (TSS) were redefined for systems with on chip antennas. The measured isotropic tangential sensitivity is lower than - $40 \mathrm{dBm}$ between $80-105 \mathrm{GHz}$, for a $10 \mathrm{kHz}$ video bandwidth. These are promising results for passive imaging applications and can be improved by increasing the antenna gain.

\section{ACKNOWLEDGMENT}

The authors wish to thank dr. Tero Kiuru from the Technical Research Center of Finland, VTT, for assisting with the sensitivity measurements.

\section{REFERENCES}

[1] A.R. Kerr, P.H. Siegel and R.J. Mattauch, "A Simple Quasi-Optical Mixer for 100-120 GHz”, 1977 IEEE MTT-S Int. Microwave Symp. Dig., pp.96,98, 21-23 June 1977

[2] D. F. Filipovic , S. S. Gearhart and G. M. Rebeiz, "Double-Slot Antennas on Extended Hemispherical and Elliptical Silicon Dielectric Lenses", IEEE Trans. Microwave Theory and Tech., vol. 41, pp.1738 1749, October 1993

[3] G. P. Gauthier, W. Y. Ali-Ahmad , T. P. Budka , D. F. Filipovic and G. M. Rebeiz, "A Uniplanar $90 \mathrm{GHz}$ Schottky-Diode Millimeter-Wave Receiver”, IEEE Trans. Microwave Theory and Tech., 1669-1672, July 1995

[4] S. Mollenkopf, L. Katehi, and G.M. Rebeiz, "A low-cost 20-22 GHz MIC active receiver/radiometer", IEEE Trans. Microwave Theory and Tech., vol.43, no.4, pp.989-993, Apr 1995

[5] H.M. Cheema, A. Shamim, "The Last Barrier: On-Chip Antennas", IEEE Microwave Magazine, vol.14, no.1, pp.79-91, Jan.-Feb. 2013

[6] M. Seyyed-Esfahlan; M. Kaynak; B. Gottel; I. Tekin, "SiGe Process Integrated On-Chip Dipole Antenna on Finite-Size Ground Plane", IEEE Antennas and Wireless Propagation Letters, vol.12, pp.1260-1263, 2013

[7] V.D. Hwang, T. Uwano, and T. Itoh, "Quasi-optical integrated antenna and receiver front end", IEEE Trans. Microwave Theory and Tech, vol.36, no.1, pp.80-85, Jan 1988

[8] I. Bahl and P. Bhartia, Microwave Solid State Circuit Design, Second Edition, New Jersey: J. Wiley \& Sons, 2003.

[9] J. Richter; R. Rehner; L. Schmidt, "A broadband low cost millimeterwave slotline detector on low permittivity substrate", IEEE European Microwave Conference, , vol.2, 4-6 Oct. 2005 